\title{
A Journal Run by Scientists
}

While looking for a reputable publisher to propose my own journal, Mr. Beall's blog (http://scholarlyoa.com) astonished me. An accumulated list of over 740 Predatory Publishers (Beall 2012a, Beall 2012b) contains many names, which often show up in my email box.

Is there any uncorrupted publishers? Yes, there are decent open-access publishers. Blue chip companies hosting hundreds of journals which charge \$2000-5000 per accepted manuscript. Few small publishers charge a reasonable amount of money, but only can host less than ten journals due to limited sources.

Can scientists operate our own journal? We surely can. We are trained to be able to learn anything. This kind of successful stories is rare, but always inspiring us. By launching this journal, I want to show our scientific attitudes.

\section{Our Scientific Attitudes}

A scientific journal should be run by scholars, scientists, researchers, and engineers. Since we are not businessmen, we mind scientific values.

Making a good journal is the most important thing. I have seen that a SCI journal decreased its impact factor from 1.5 to 0.3 within 5 years, and understood how hard to maintain a reputable publication. The goal of this journal is to pass EI Compendex review within 5 years, and be included in SCI index within 7 years.

In order to make a good journal and achieve these goals, it needs the collaborative effort among our editorial board members, authors, reviewers, and all contributors.

We show respect for scholars. The first two volumes of the journal are free of any charge to authors. The length of this Article Processing Charge (APC) waive period may be extended, if the editorial board thought it's necessary.

We show respect to our editors, editorial board members, and reviewers. After the APC waive period, we will waive APC for manuscripts submitted by our editorial team, and provide $50 \%$ discount to reviewers.

\section{This Journal}

Trends in Renewable Energy (U.S. ISSN: 2376-2136, online ISSN: 2376-2144) is a peer-reviewed open access journal that is run exclusively by scientists. It aims to provide a fair platform among scholars, and share our knowledge in the energy related areas. Scope of the journal covers: Renewable energy, Catalysis for energy generation, Biofuel, Bioenergy, Biomass, Biorefinery, Biological waste treatment, Bioprocessing, Energy conservation, Energy Resources, Energy transformation, Energy storage, Environmental impact, Feedstock utilization, Future energy development, Green chemistry, Green energy, Microbial products, Physico-chemical process for biomass, Policy, Pollution, Thermo-chemical processes for biomass, etc. We publish the following article types: reviews, mini-reviews, technical notes, short-form original research papers, and research papers.

Bo Zhang

Editor in Chief 


\section{REFERENCES}

Beall, J. (2012a). "Predatory publishers are corrupting open access." Nature, 489, 179. DOI: $10.1038 / 489179$ a

Beall, J. (2012b). "Criteria for determining predatory open." http://scholarlyoa.com/2012/11/30/criteria-for-determining-predatory-openaccess-publishers-2nd-edition/. [Accessed on October 3, 2014]

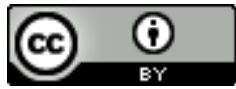

This work is licensed under a Creative Commons Attribution 4.0 International License. 